\title{
Does Patients' Perception Affect Self-Care Practices? The Perspective of Health Belief Model
}

\author{
Lydia Melkamu' \\ Resom Berhe ${ }^{2}$ \\ Simegnew Handebo ${ }^{2}$ \\ 'Department of Health Promotion and \\ Behavioral Sciences, College of Medicine \\ and Health Sciences, Bahir Dar \\ University, Bahir Dar, Ethiopia; \\ ${ }^{2}$ Department of Health Education and \\ Behavioral Sciences, Institute of Public \\ Health, College of Medicine and Health \\ Sciences, University of Gondar, Gondar, \\ Ethiopia
}

Background: Poor lifestyle choices contribute to the continued growth of chronic illness and disability. Patients with diabetes require continuous self-care choices and management to minimize the short- and long-term impact of the disease. This study aimed at assessing the use of the health belief model to describe self-care practices among patients with diabetes.

Methods: An institutional-based cross-sectional study was conducted from February to March 2019 in Gondar City, Northwest Ethiopia. A total of 396 diabetics patients were selected using a systematic random sampling technique. Pretested, structured, and interview administered questionnaire was used for data collection. The collected data were analyzed using STATA 14. Bivariate and multivariate logistic regression models were fitted to identify the factors associated with self-care behavior. Adjusted odds ratio (AOR) with $95 \%$ confidence interval (CI) and p-values $<0.05$ were used to declare statistical association.

Results: Health belief model described $48 \%$ of the variance in self-care practices of patients with diabetes. More than half (55.6\%) of diabetic patients had good self-care practice. Of the participants, $45.8 \%$ and $49.9 \%$ had low perceived susceptibility and perceived severity, respectively. The strongest correlation was found between cues to action and perceived severity of health belief model constructs $(\mathrm{P}<0.001)$. Formal education, longer duration of diabetes, high social support, high perceived severity, and high self-efficacy contributed to good self-care practices, whereas comorbidities, high perceived benefit, and high perceived barrier were associated with poor self-care practices.

Conclusion: Self-care practice of diabetes patients in Gondar City was considerably low. Health professionals need to strengthen delivering tailored health messages on the benefit self-care practices and means of overcoming the potential barriers. Health communication programs are also better to consider for individuals with comorbidities, lack of social support, and lower education.

Keywords: self-care practice, diabetes, health belief model, University of Gondar

\section{Background}

Diabetes Mellitus (DM) is a group of metabolic disorders characterized by high levels of blood glucose resulting from defects in insulin production, action, or both. ${ }^{1}$ Diabetes is a growing global health problem, with the fastest growth rates occurring in low- and middle-income countries. Reduced physical activity, sedentary lifestyles, and aging make people more likely to develop diabetes. To avoid life-threatening organ damage and premature death, patients with diabetes needs a larger, more systematic, and continuous medical treatment with multi-factorial risk-reduction methods beyond glycemic control. ${ }^{2,3}$
Correspondence: Simegnew Handebo Department of Health Education and Behavioral Sciences, Institute of Public Health, College of Medicine and Health Sciences, University of Gondar, P.O. Box

196, Gondar, Ethiopia

Tel +25I-9l2-490659

Email simegnewh@gmail.com 
The number of people with diabetes is increasing. ${ }^{4}$ According to the World Health Organization (WHO), the prevalence of diabetes in adults aged 18-99 years was $8.4 \%$ in 2017 and is expected to increase to $9.9 \%$ by $2045 .^{5}$ In 2015 , in the Africa 14.2 million (3.2\%) adults aged 20-79 years had diabetes. The prevalence of diabetes in Ethiopia ranged from $0.3 \%$ to $7.0 \%{ }^{6}$ International Diabetes Federation (IDF) estimated that nearly 50 million deaths were attributed to diabetes among people aged 20-99 years in $2017 .^{7}$ The proportion of all deaths attributed to diabetes in the Africa and Ethiopia was $73.7 \%$ and $2.05 \%$, respectively. 8,9

Increased prevalence of diabetes has social, financial, and development implications, especially in low- and middle-income countries. This get worse in economically disadvantaged countries like Ethiopia, where there is limited access of healthcare. ${ }^{8,10}$ Uncontrolled DM results in heart attacks and strokes, 2 to 6 times higher than diabetes-free people and shorten lifespan by $10-15$ years. ${ }^{8} \mathrm{DM}$ also affects quality of life of individuals and leads to poor health outcome. Long-term damage, dysfunction, and failure of various organs including blindness, nerve damage, end-stage kidney disease, and amputations of the feet and legs in adults are the effects of DM. ${ }^{11}$

Self-care practice has multiple domains, including food choices, physical activity, proper medication intake, and blood glucose monitoring as well self-care measures to prevent injury at the lower extremities. ${ }^{12}$ Regardless of the type of diabetes, self-care is critical for achieving glycemic control and avoiding or delaying severe complications. ${ }^{13,14}$ It influences one's way of life, resulting in improvements in quality of life, perceived health, resource use, complications, and healthcare costs. ${ }^{15}$ Self-care is the heart of diabetes treatment and its effectiveness. ${ }^{16,17}$ However, self-care practices among diabetic patients in Sub-Saharan African countries are low. In Ethiopia, studies showed that self-care practices ranged from $39 \%$ to $76.8 \% .^{18-23}$ In the study area, more than half of patients have poor self-care practice. ${ }^{24}$ Another study found that having a high perceived severity of diabetes and a low perceived barrier to self-care increase the adoption of self-care activities. ${ }^{20}$

The health belief model (HBM) (Figure 1) was developed to explain the widespread failure of people to participate in programs to prevent and detect disease. HBM is a known framework to understand why patients do/do not engage in the preventive measures of a certain disease. ${ }^{25}$ The perceptions towards DM and self-care practice affects the adoption and maintenance of self-care practices. According to the model, for the behavior (self-care practice) to succeed, patients must feel threatened by their poor self-care practice (perceived susceptibility and severity),

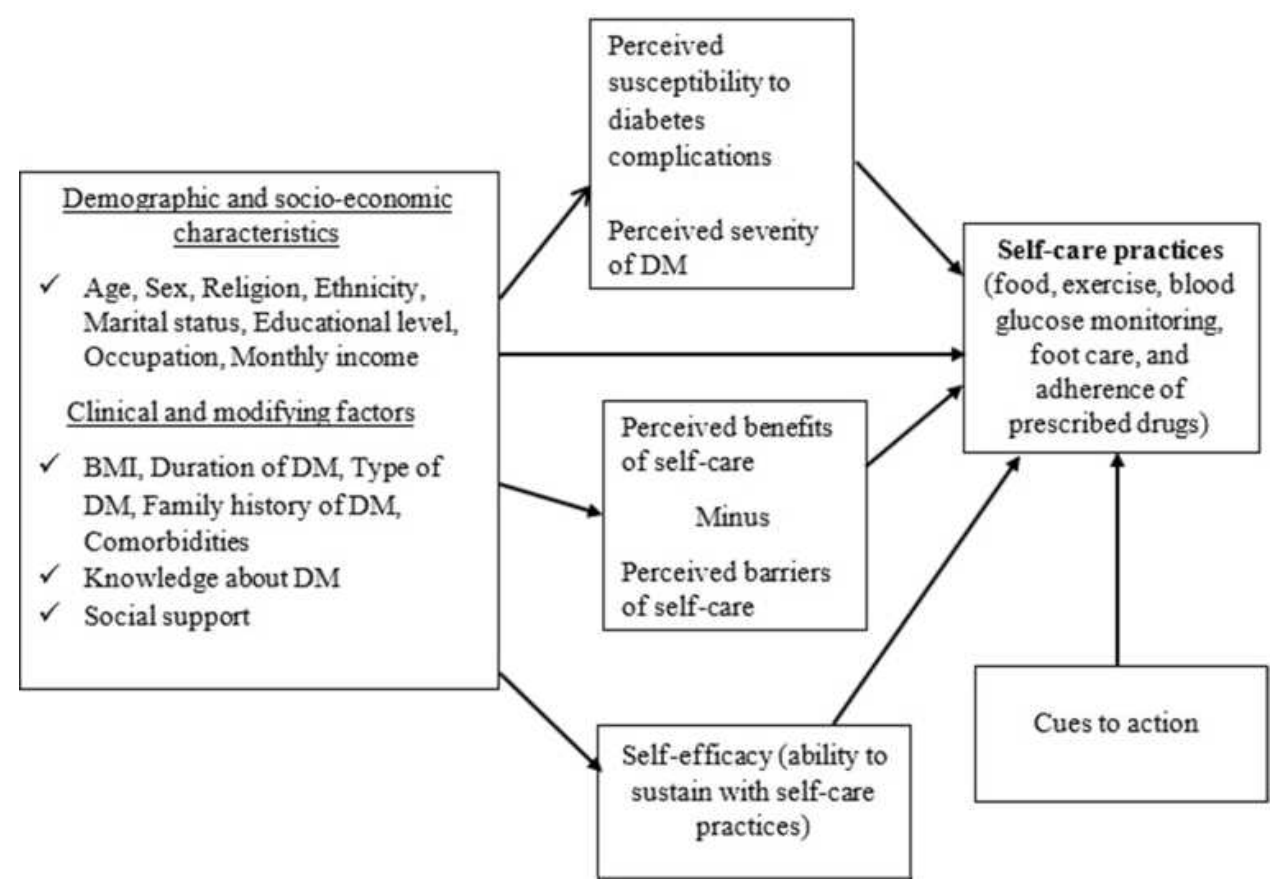

Figure I Health belief model used to assess self-care practice and associated factors among diabetic patients in Gondar City. Note: Data adapted from Glanz et al. ${ }^{25}$ 
believe that change in self-care practice result in a valued outcome at an acceptable cost (perceived benefit), and feel competent (self-efficacy) to overcome perceived barriers to take action. This means, patient's engagement in self-care practices increase with high perceived susceptible to the illness, greater severity of the illness and its complications, high perceived benefit of and lower barrier to self-care practices, more cues to action and greater selfefficacy. ${ }^{20,25,26}$ This study assessed the use of the health belief model to describe self-care behavior among patients with diabetes in Gondar City, northwest Ethiopia. It addressed prevalence of self-care practice, the factors to influence self-care behavior, and the influence between the HBM constructs and self-care behavior.

\section{Methods}

\section{Study Setting and Design}

An institution-based cross-sectional study was conducted from February to March 2019. The study was conducted in University of Gondar Specialized Hospital located in Gondar city. The City is found in central Gondar zone of Amhara regional state located $727 \mathrm{~km}$ Northwest of Addis Ababa with a total estimated population of 323,900 . The hospital is one of the tertiary health care facility in Ethiopia and Amhara region and serves more than 5 million people in the catchment area. It serves over 24,552 people living with chronic follow-up per year. It has an outpatient diabetes service twice per week with the mean flow of 900 diabetic patients per month.

\section{Sample Size and Sampling Procedure}

The sample size was determined using single population proportion formula using Epi info 7 statistical software. The assumptions in the calculation of the sample size were 95\% confidence interval (CI), marginal error (d) of 5\%, and $10 \%$ non-response rate and $36.8 \%$ proportion of diabetic patients who had good self-care practice in Felege Hiwot hospital. ${ }^{27}$ The final sample size was 396 participants.

All patients with diabetes aged greater than 18 years and had a regular follow for at least six months at University of Gondar Specialized Hospital were included in the study. Whereas, patients who were seriously ill and unable to respond to the questions were excluded. A systematic random sampling method was used to the recruit the study participants. On average every month about 900 patients will visit the follow-up center. The sampling interval " $K$ " value was calculated as $K=\mathrm{N} / \mathrm{n}$, where $\mathrm{N}=$ the expected number of diabetes patients per month $=900$ and $\mathrm{n}=$ sample size $=398$ which gives a sampling interval of two. Thus, study subjects were selected in every 2 intervals and the first participant was selected by lottery method.

\section{Data Collection Tools and Measurement}

Data was collected using interview administered structured questionnaire. The questionnaire includes socio demographic, clinical and modifiable factors, and constructs of HBM. The Summary of Diabetes Self-Care Activities (SDSCA) scale was used to measure the frequency of selfcare practices in the last seven days in the five domains: food, exercise, foot care, medication and self-monitoring of blood glucose. Eleven questions were used to assess selfcare behavior. ${ }^{28}$ SDSCA was calculated by summing up the mean score for each dimension divided by the sum of the number of questions under each scale. Ten of the fourteen Diabetes Knowledge Test (DKT) questionnaire was used to measure patient's knowledge about Diabetes. ${ }^{29}$ The social support questions were adopted from previously validated tools of chronic illness resources survey (CIRS) with the internal consistency Cronbach's alpha coefficient of $0.71 .^{30}$ It contains 5 items rated on a 5-point Likert scale: not at all (1), a little (2), a moderate amount (3), quite a bit (4), and a great deal (5). The HBM constructs were assessed using modified versions of scales validated by champions and colleagues. ${ }^{31}$ Thirty-five [perceived susceptibility (6 items), perceived severity ( 7 items), perceived benefit ( 7 items), perceived barrier ( 7 items), self-efficacy ( 3 items), and cues to action (5 items)] Likert scale items with 5-points ( $1=$ strongly disagree to $5=$ strongly agree) were used to assess the perception of participants about DM and self-care practices. Internal consistency for HBM model as measured by the Cronbach's alpha coefficient was ranged from 0.79 to 0.94 .

\section{Operational Definition}

Self-care practice: We measured diabetes self-care practice in the last seven days using five domains: dietary practices, regular exercise, foot care, medication, and blood glucose monitoring. It was measured by eleven items. Self-care was defined as "good" if respondents scored the mean and above of the overall self-care practice score. ${ }^{19-23,26}$ 
Diabetic knowledge: was measured by ten items and recoded as "good" if participants respond five and above out of the total knowledge questions.

Health belief model constructs: (perceived susceptibility, perceived severity, perceived benefit, perceived barrier, self-efficacy, and cues to action) and social support were measured as high, medium, and low if the respondents scored above $75 \%$, between $50 \%$ and $75 \%$, and below $50 \%$ of the summed score of five-point Likert scale questions, respectively.

\section{Data Quality Control}

Content validity was done with 6 experts and pretested among 20 patients at Felege Hiwot Referral hospital. The questionnaire was first prepared in English and then translated to local language (Amharic) and back to English for checking the consistency. The data was collected by trained six Nurses. The data collectors took two days training on the objective, methods and ethics of the study. One health officer supervised the overall data collection process. Data cleaning and cross checking was done on daily basis.

\section{Data Processing and Analysis}

The collected data were coded and entered in to EPI INFO version 7 and exported to STATA version 14 for analysis. Multicollinearity among the independent variables was assessed using variance inflation factors (VIF) and was in the acceptable range. Frequencies and cross tabulations were used to summarize descriptive statistics and tables were used for data presentation. Correlational analysis was done between the constructs of the HBM to identify the relationship between each construct. Bivariable and multi-variable logistic regression were fitted to control the possible effect of confounders. All variables with a p-value $<0.25$ at bivariable logistic regression analysis were entered into the multivariable logistic regression model. P value $<0.05$ was used to declare statistically significant variables.

\section{Results}

\section{Socio Demographic Characteristics}

A total of 387 eligible patients participated in the study with a response rate of $97.7 \%$. The mean age of respondents was 48 ( $\mathrm{SD} \pm 16)$ years. Out of the respondents $205(52.9 \%)$ were male, $330(85 \%)$ were orthodox in religion, $339(87.6 \%)$ were Amhara by ethnicity, and 222 (57\%) were married. One hundred twenty-one (37.3\%) respondents had no formal
Table I Socio-Demographic and Economic Characteristics of Diabetic Patients University of Gondar Specialized Hospital, Northwest Ethiopia, $2019(n=387)$

\begin{tabular}{|c|c|c|}
\hline Variables & Description & Frequency (\%) \\
\hline \multirow[t]{5}{*}{ Age } & $18-29$ & $61(15.7)$ \\
\hline & $30-39$ & $70(18.1)$ \\
\hline & $40-49$ & $52(13.4)$ \\
\hline & $50-59$ & $86(22.2)$ \\
\hline & $\geq 60$ & $118(30.5)$ \\
\hline \multirow[t]{2}{*}{ Sex } & Male & $205(53)$ \\
\hline & Female & $182(47)$ \\
\hline \multirow{3}{*}{ Religion } & Orthodox & $330(87.3)$ \\
\hline & Muslim & $50(12.9)$ \\
\hline & Protestant & $7(1.8)$ \\
\hline \multirow[t]{3}{*}{ Ethnicity } & Amhara & $339(87.6)$ \\
\hline & Kimant & $31(8)$ \\
\hline & Tigre & $17(4.4)$ \\
\hline \multirow[t]{4}{*}{ Marital status } & Married & $222(57.6)$ \\
\hline & Single & $97(25.1)$ \\
\hline & Widowed & $44(I I .4)$ \\
\hline & Divorced & $24(6.2)$ \\
\hline \multirow[t]{4}{*}{ Educational status } & No formal education & $|2|(3 \mid .3)$ \\
\hline & Primary education & $112(28.9)$ \\
\hline & Secondary education & $69(17.8)$ \\
\hline & Diploma and above & $85(21.9)$ \\
\hline \multirow[t]{3}{*}{ Employment status } & Government employed & $70(18.1)$ \\
\hline & Private employed & I 44 (37.2) \\
\hline & Unemployed & $173(44.7)$ \\
\hline \multirow[t]{4}{*}{ Income } & $\leq 999$ & $82(2 \mid .2)$ \\
\hline & $1000 / 1999$ & $128(33.1)$ \\
\hline & $2000 / 2999$ & $63(16.3)$ \\
\hline & $\geq 3000$ & $114(29.5)$ \\
\hline
\end{tabular}

education. The mean average monthly income of the respondents was 2024.31 (SD \pm 1443.94) Ethiopian Birr (Table 1).

\section{Clinical Characteristics}

Of the respondents $184(47.55 \%)$ had DM for less than five years and Type II diabetes accounting for the majority 215 (55.6\%). Nearly one-fourth 96 (24.8\%) of the respondents had comorbidity (Table 2).

\section{Health Belief Model Constructs}

About half of the participant had low perceived susceptibility $177(45.8 \%)$ and perceived severity 193 (49.9\%). The majority of the respondents 255 (65.9\%) had medium self-efficacy (Table 3 ). Perceived severity 
Table 2 Clinical Characteristics of Diabetic Patients in University of Gondar Specialized Hospital, Northwest Ethiopia, 2019 $(n=387)$

\begin{tabular}{|c|c|c|}
\hline Variable & Description & $\begin{array}{l}\text { Frequency } \\
\text { (\%) }\end{array}$ \\
\hline Time since diagnosis & $\begin{array}{l}<5 \text { years } \\
5-10 \text { years } \\
\geq 10 \text { years }\end{array}$ & $\begin{array}{l}184(47.5) \\
119(30.8) \\
84(21.7)\end{array}$ \\
\hline Type of diabetes & $\begin{array}{l}\text { Type I } \\
\text { Type II }\end{array}$ & $\begin{array}{l}172(44.4) \\
215(55.6)\end{array}$ \\
\hline Body mass index & $\begin{array}{l}\text { Underweight } \\
\text { Normal weight } \\
\text { Overweight } \\
\text { Obese }\end{array}$ & $\begin{array}{l}18(4.64) \\
181(46.8) \\
147(37.9) \\
41(10.6)\end{array}$ \\
\hline Comorbidities & $\begin{array}{l}\text { Yes } \\
\text { No }\end{array}$ & $\begin{array}{l}96(24.8) \\
291(75.2)\end{array}$ \\
\hline Family history of DM & $\begin{array}{l}\text { Yes } \\
\text { No }\end{array}$ & $\begin{array}{l}61(15.7) \\
326(84.3)\end{array}$ \\
\hline Social support & $\begin{array}{l}\text { High social support } \\
\text { Medium social } \\
\text { support } \\
\text { Low social support }\end{array}$ & $\begin{array}{l}100(25.8) \\
139(35.9) \\
148(38.2)\end{array}$ \\
\hline $\begin{array}{l}\text { Knowledge about } \\
\text { diabetes }\end{array}$ & $\begin{array}{l}\text { Good knowledge } \\
\text { Poor knowledge }\end{array}$ & $\begin{array}{l}228(58.9 \%) \\
159(4 \mid .1)\end{array}$ \\
\hline
\end{tabular}

Table 4 Correlation Between Health Belief Model Constructs $(n=387)$

\begin{tabular}{|l|l|l|l|l|l|l|}
\hline Variable & $\mathbf{I}$ & $\mathbf{2}$ & $\mathbf{3}$ & $\mathbf{4}$ & $\mathbf{5}$ & $\mathbf{6}$ \\
\hline I. Perceived & 1 & & & & & \\
susceptibility & & & & & & \\
2. Perceived severity & $0.17^{* *}$ & 1 & & & & \\
3. Perceived benefit & -0.005 & 0.05 & 1 & & & \\
4. Perceived barrier & 0.04 & $-0.13^{*}$ & -0.28 & 1 & & \\
5. Self-efficacy & -0.03 & $0.15^{* *}$ & $0.36^{* *}$ & -0.29 & 1 & \\
6. Cues to action & 0.06 & $0.86^{* *}$ & $0.28^{* *}$ & $-0.31^{* *}$ & $0.33^{* *}$ & 1 \\
\hline
\end{tabular}

Note: significant level $* *<0.001, *<0.01$.

was correlated positively with perceived susceptibility, and negatively with perceived barrier. Self-efficacy was positively correlated with perceived severity and perceived benefit. The strongest correlation was observed between cues to action and perceived severity (Table 4).

\section{Self-Care Practices and Knowledge About DM}

Of the total respondents, $55.6 \%(95 \% \mathrm{CI}=50.54,60.45)$ of them had good self-care practices. Besides, more than half of 228 (58.9\%) had good knowledge about diabetes.

Table 3 Perceptions of Diabetic Patients in University of Gondar Specialized Hospital About DM and Self-Care Practice, Northwest Ethiopia, $2019(n=387)$

\begin{tabular}{|c|c|c|c|c|}
\hline Variable & Description & Good Self-Care (\%) & Poor Self-Care (\%) & Total (\%) \\
\hline \multirow[t]{3}{*}{ Perceived susceptibility } & High & $58(50)$ & $58(50)$ & $116(30)$ \\
\hline & Medium & $59(62.6)$ & $35(37.2)$ & $94(24.2)$ \\
\hline & Low & $98(55.4)$ & $79(44.6)$ & $177(45.8)$ \\
\hline \multirow[t]{3}{*}{ Perceived severity } & High & $85(70.8)$ & $35(29.2)$ & $120(31)$ \\
\hline & Medium & $48(64.9)$ & $26(35.1)$ & $74(19.1)$ \\
\hline & Low & $82(42.5)$ & $\mathrm{III}(57.5)$ & 193(49.9) \\
\hline \multirow[t]{3}{*}{ Perceived benefit } & High & $50(62.5)$ & $30(37.5)$ & $80(20.7)$ \\
\hline & Medium & $109(54.2)$ & $92(45.8)$ & $20 I(51.9)$ \\
\hline & Low & $56(52.8)$ & $50(47.2)$ & $106(27.4)$ \\
\hline \multirow[t]{3}{*}{ Perceived barrier } & High & $28(27.4)$ & $74(72.6)$ & $102(26.4)$ \\
\hline & Medium & $63(50.4)$ & $62(49.6)$ & $125(32.3)$ \\
\hline & Low & $124(77.5)$ & $36(22.5)$ & $160(41.3)$ \\
\hline \multirow[t]{3}{*}{ Self-efficacy } & High & $45(66.2)$ & $23(33.8)$ & $68(17.5)$ \\
\hline & Medium & $162(63.5)$ & $93(36.5)$ & $255(65.9)$ \\
\hline & Low & $8(12.5)$ & $56(87.5)$ & $64(16.5)$ \\
\hline \multirow[t]{3}{*}{ Cues to action } & High & $92(66.2)$ & $47(33.8)$ & $139(35.9)$ \\
\hline & Medium & $55(67.1)$ & $27(32.9)$ & $82(21.1)$ \\
\hline & Low & $68(4 I)$ & $98(59)$ & $166(43)$ \\
\hline
\end{tabular}




\section{Factors Associated with Self-Care Practices}

The HBM described nearly $48 \%$ of variance of self-care practice among patients with diabetes. In multivariable logistic regression marital status, educational status, employment status, duration of diabetics, comorbidity, knowledge about DM, social support, perceived severity, perceived benefit, perceived barriers, and self-efficacy were factors significantly associated with self-care practices having $\mathrm{p}$-value $<0.05$.

Married individuals had 3 times more likely engaged in self-care practices than singles (AOR $=3.12,95 \%$ CI: 1.27 , 7.69). Compared to those who had no formal education, individuals who attended primary education $(\mathrm{AOR}=5.00$, $95 \%$ CI: $2.40,19.72)$, secondary education $(\mathrm{AOR}=6.89$, 95\% CI=1.55-9.77), and diploma and above (AOR 7.68, 95\% CI: $2.19,26.96$ ) were more likely engage in self-care practices. Unemployed individuals were 3.5 times more likely engaged in self-care practices than who employed in government institutions ( $\mathrm{AOR}=3.5095 \% \mathrm{CI}$ : 1.06, 11.51). Individuals with $\mathrm{DM}$ duration of $5-10$ years $(\mathrm{AOR}=2.23$, 95\% CI: $1.10,4.51)$ and above 10 years $(\mathrm{AOR}=7.88,95 \%$ $\mathrm{CI}=3.02,20.53)$ were more likely engaged in self-care practices than those with less than five years.

Patients who had good knowledge about DM (AOR= 3.31, 95\% CI: 1.66, 6.60), high social support (AOR= 4.88, 95\% CI: 2.00, 11.90), medium perceived severity $(\mathrm{AOR}=2.46,95 \% \mathrm{CI}: 1.06,5.73)$, high perceived severity $(\mathrm{AOR}=4.57,95 \% \mathrm{CI}: 2.11,9.93)$, medium self-efficacy (AOR $=9.43,95 \%$ CI: 2.86, 31.1), and high self-efficacy $(\mathrm{AOR}=9.12,95 \%$ CI: $2.28,36.48)$ were more likely engaged in self-care practices. Whereas, individuals who had comorbidities (AOR $=0.34,95 \%$ CI: 0.16, 0.76), medium perceived benefit $(\mathrm{AOR}=0.32,95 \% \mathrm{CI}: 0.14,0.72)$, high perceived benefit ( $\mathrm{AOR}=0.26,95 \% \mathrm{CI}: 0.09,0.73$ ), and high perceived barrier ( $\mathrm{AOR}=0.21,95 \% \mathrm{CI}: 0.08$, $0.50)$ were less likely engaged in self-care practices (Table 5).

\section{Discussion}

This study assessed the role of perceptions (HBM constructs) towards DM and self-care practice in adoption of self-care practices among DM patients. The model described nearly $48 \%$ of variance of self-care practice among DM patients. It is relatively good predictor of selfcare in the study population. Studies done in Iran found that the HBM constructs accounted for $29.6 \%$ and $33.5 \%$ variance of self-care practice. ${ }^{32,33}$ But the current finding is lower than study done in Hazrat Ali Asghar hospital, which reported as the HBM described $59.9 \%$ of the variance of self-care practice. ${ }^{34}$ The discrepancy may be due to the differences in susceptibility, benefits, and barriers beliefs among the population groups.

This study revealed DM patients had inadequate level of self-care practices. Overall, 55.6\% DM patients had good self-care practices. This finding was in-line with studies conducted in Gumuz (54.3\%), Mekele (51\%), and Addis Ababa (60.3\%). ${ }^{19,22,35}$ But lower than a study conducted in Dilla town $(76.8 \%),{ }^{21}$ and higher than studies done in Harar, Felege Hiwot, and Bahir Dar. ${ }^{20,27,36}$ The possible explanation for this may be due to time gap, socio economic, and life style differences in the study population.

Married individuals more likely adhere to self-care practice. This may be due to support from their spouse in adhering with recommended self-care practices. Previous studies did not identify a significant association between marital status and self-care practice. ${ }^{22,31}$ Unlike to a study done in Malaysia, individuals who had a formal education were more likely to adhere to self-care practices than those with no formal education. ${ }^{37}$ Similar finding was reported by other studies. ${ }^{20,23,28}$ The potential explanation could be education enhance one's confidence and ability to make health-related decisions. Also, educated people can easily access and use health messages. Unemployed patients were also found to be more involved in self-care practices in the current research. This study result contrasts with finding reported by studies done in Tigray and Nekemte Hospital. ${ }^{19,38}$ Employed individuals are more likely engaged in self-care practice than unemployed people. ${ }^{33}$ The possible explanation might be confounding factors that enabled unemployed patients to engage in self-care practices.

In-line with a study conducted in the USA, patients with comorbidity were less likely perform self-care practices. ${ }^{39}$ This may be because of competing regimen. Moreover, the longer duration of DM was associated with a higher self-care practice. This finding is supported by studies conducted Ethiopia, Nepal, and Greece. ${ }^{27,40,41}$ This may be due to the more they have the disease, the more they learn about it and how to care for themselves. Similarly, as reported by studies conducted in Ethiopia, Bangladesh, and Ghana, patients with good knowledge about DM were more likely engaged in self-care practice. $^{22,42,43}$ Knowledge enhances the confidence to 
Table 5 Bivariable and Multivariable Logistic Regression of Self-Care Practice of Diabetic Patients in University of Gondar Specialized Hospital, Northwest Ethiopia, 2019 ( $n=387)$

\begin{tabular}{|c|c|c|c|c|}
\hline Variables & Description & COR $(95 \% \mathrm{Cl})$ & AOR (95\% Cl) & $P$ value \\
\hline Age (mean $\pm S D)^{\star}$ & $48( \pm 16)$ & $0.99(0.97,1.01)$ & $1.00(0.97,1.03)$ & 0.98 \\
\hline Marital status & $\begin{array}{l}\text { Single } \\
\text { Married } \\
\text { Widowed } \\
\text { Divorced }\end{array}$ & $\begin{array}{l}\text { I } \\
1.29(0.79,2.09) \\
0.63(0.31,1.29) \\
0.42(0.16,1.06)\end{array}$ & $\begin{array}{l}\text { I } \\
3.12(1.27,7.69) \\
3.44(0.89,13.36) \\
0.52(0.13,2.08)\end{array}$ & $\begin{array}{l}0.013^{*} \\
0.074 \\
0.353\end{array}$ \\
\hline Religion & $\begin{array}{l}\text { Orthodox } \\
\text { Muslim } \\
\text { Protestant }\end{array}$ & $\begin{array}{l}\text { I } \\
\text { I.54 (0.83-2.84) } \\
5.18(0.62-43.5)\end{array}$ & $\begin{array}{l}\text { I } \\
2.19(0.79,6.07) \\
1.43(0.10,30.3)\end{array}$ & $\begin{array}{l}0.134 \\
0.817\end{array}$ \\
\hline Educational status & $\begin{array}{l}\text { No formal education } \\
\text { Primary education } \\
\text { Secondary education } \\
\text { Diploma and above }\end{array}$ & $\begin{array}{l}\text { I } \\
3.67(2.12-6.34) \\
5.46(2.87-10.39) \\
10.23(5.27-19.86)\end{array}$ & $\begin{array}{l}\text { I } \\
5.00(2.17,11.57) \\
6.89(2.40,19.72) \\
7.68(2.19,26.96)\end{array}$ & $\begin{array}{l}0.000 * * \\
0.000^{* *} \\
0.001 * *\end{array}$ \\
\hline Employment status & $\begin{array}{l}\text { Government employ } \\
\text { Private employ } \\
\text { Unemployed }\end{array}$ & $\begin{array}{l}\text { I } \\
0.37(0.20,0.69) \\
0.42(0.23,0.78)\end{array}$ & $\begin{array}{l}\text { I } \\
1.66(0.50,5.49) \\
3.50(1.06,11.51)\end{array}$ & $\begin{array}{l}0.403 \\
0.039 *\end{array}$ \\
\hline Duration of diabetes & $\begin{array}{l}<5 \text { years } \\
5-10 \text { years } \\
\geq 10 \text { years }\end{array}$ & $\begin{array}{l}1 \\
1.96(1.23,3.13) \\
7.10(3.73,13.53)\end{array}$ & $\begin{array}{l}I \\
2.23(I .10,4.5 I) \\
7.88(3.02,20.53)\end{array}$ & $\begin{array}{l}0.026 * \\
0.000 * *\end{array}$ \\
\hline Comorbidities & $\begin{array}{l}\text { No } \\
\text { Yes }\end{array}$ & $\begin{array}{l}\text { I } \\
0.29(0.18-0.48)\end{array}$ & $\begin{array}{l}\text { I } \\
0.34(0.16,0.76)\end{array}$ & $0.008 * *$ \\
\hline Family history & $\begin{array}{l}\text { No } \\
\text { Yes }\end{array}$ & $\begin{array}{l}\text { I } \\
1.64(0.93-2.90)\end{array}$ & $\begin{array}{l}\text { I } \\
0.85(0.32,2.27)\end{array}$ & 0.744 \\
\hline Knowledge about DM & $\begin{array}{l}\text { Poor knowledge } \\
\text { Good knowledge }\end{array}$ & $\begin{array}{l}\text { I } \\
6.01(3.85,9.38)\end{array}$ & $\begin{array}{l}\text { I } \\
3.31(1.66,6.60)\end{array}$ & $0.001 * *$ \\
\hline Social support & $\begin{array}{l}\text { Low } \\
\text { Medium } \\
\text { High }\end{array}$ & $\begin{array}{l}\text { I } \\
\text { I.77 (I.10-2.82) } \\
5.5 \text { I (3.08-9.87) }\end{array}$ & $\begin{array}{l}\text { I } \\
1.60(0.80,3.23) \\
4.88(2.00,11.90)\end{array}$ & $\begin{array}{l}0.186 \\
0.000 * *\end{array}$ \\
\hline Perceived susceptibility & $\begin{array}{l}\text { Low } \\
\text { Medium } \\
\text { High }\end{array}$ & $\begin{array}{l}\text { I } \\
\text { I.36 }(0.81,2.27) \\
0.81(0.50,1.29)\end{array}$ & $\begin{array}{l}\text { I } \\
\text { I.42(0.62, 3.24) } \\
0.98(0.45,2.12)\end{array}$ & $\begin{array}{l}0.403 \\
0.952\end{array}$ \\
\hline Perceived severity & $\begin{array}{l}\text { Low } \\
\text { Medium } \\
\text { High }\end{array}$ & $\begin{array}{l}\text { I } \\
2.49(1.43-4.35) \\
3.28(2.02-5.34)\end{array}$ & $\begin{array}{l}\text { I } \\
2.46(1.06,5.73) \\
4.57(2.11,9.93)\end{array}$ & $\begin{array}{l}0.037^{*} \\
0.000 * *\end{array}$ \\
\hline Perceived benefit & $\begin{array}{l}\text { Low } \\
\text { Medium } \\
\text { High }\end{array}$ & $\begin{array}{l}\text { I } \\
\text { I.06 }(0.66,1.70) \\
\text { I. } 49(0.82,2.69)\end{array}$ & $\begin{array}{l}\text { I } \\
0.32(0.14,0.72) \\
0.26(0.09,0.73)\end{array}$ & $\begin{array}{l}0.006 * * \\
0.011 *\end{array}$ \\
\hline Perceived barrier & $\begin{array}{l}\text { Low } \\
\text { Medium } \\
\text { High }\end{array}$ & $\begin{array}{l}\text { I } \\
0.29(0.17,0.49) \\
0.11(0.06,0.19)\end{array}$ & $\begin{array}{l}\text { I } \\
0.49(0.23,1.06) \\
0.21(0.08,0.50)\end{array}$ & $\begin{array}{l}0.069 \\
0.001 * *\end{array}$ \\
\hline Self-efficacy & $\begin{array}{l}\text { Low } \\
\text { Medium } \\
\text { High }\end{array}$ & $\begin{array}{l}\text { I } \\
\text { I2.19 (5.57, 26.69) } \\
\text { I3.69 (5.59, 33.52) }\end{array}$ & $\begin{array}{l}\text { I } \\
9.43(2.86,31.10) \\
9.12(2.28,36.48)\end{array}$ & $\begin{array}{l}0.000 \text { ** } \\
0.002 \text { ** }\end{array}$ \\
\hline
\end{tabular}


Table 5 (Continued).

\begin{tabular}{|l|l|l|l|l|}
\hline Variables & Description & COR $(\mathbf{9 5} \% \mathbf{C I})$ & AOR $\mathbf{( 9 5 \% ~ C l )}$ & $\mathbf{P}$ value \\
\hline Cues to action & Low & $\mathrm{I}$ & $\mathrm{I}$ & \\
& Medium & $2.93(1.68,5.1 \mathrm{I})$ & $1.34(0.55,3.27)$ & 0.525 \\
& High & $2.82(1.76,4.50)$ & $1.52(0.71,3.26)$ & 0.279 \\
\hline
\end{tabular}

Note: ${ }^{*}$ Continuous variable; $* *$ Significant at $p$-value $\leq 0.01$; *significant at $p$-value $\leq 0.05$.

Abbreviations: AOR, adjusted odds ratio; COR, crude odds ratio.

make decisions and adjust one's lifestyle. Similarly, individuals with higher social support were more likely engaged in self-care practices. This finding was supported by previous studies. ${ }^{22,36,41,44}$ This may be because social support motivates and offers moral support for adopting recommended practices.

Individuals with a high perceived severity of the disease and self-efficacy were more likely to practice selfcare. Besides, people with high perceived barrier were less likely to practice self-care. A study also found that perceived benefit to be related with a good self-care practice while perceived barrier linked with poor self-care practice. ${ }^{19}$ A study done in Harari reported people with high perceived severity of diabetes and less perceived barrier to self-care were more likely to engaged in selfcare practices. $^{20}$ The study in Nigeria also reported a positive association of DM management with perceived severity and perceived benefits. ${ }^{45}$ Similar to our finding, studies reported that patients with high self-efficacy were more likely perform self-care practice..$^{23,46}$

In contrast to the assumptions of the HBM and studies done, our study found individuals with high perceived benefit of self-care were less likely to practice self-care. ${ }^{33,45}$ This may be due to the imbalance between perceived benefits and barriers resulting in a lower net benefit. Although the patients have high perceived benefit and positive expectation, the barriers became an obstacle to engaging in selfcare practices. Unlike to a study done in Iran, no significant association was identified between perceived susceptibility and self-care practice. ${ }^{34}$ Similar finding was reported by a study conducted in Nigeria. ${ }^{45}$ This might be due to lack of knowledge about the disease which decreases the perceived susceptibility of the patients.

The study findings should be considered with its limitations. There may be recall and social desirability bias. But study explored self-care practice executed in the past seven days, which minimize the recall bias. HBM did not give room to examining cultural and environmental factors which may affect. Since the study was cross-sectional in design, the causal relationship was not determined.

\section{Conclusion}

The self-care practice of DM patients was considerably low. Thus, evaluating self-care practice of the patients ought to be part integrated management and providing timely intervention is important to enhance the practice. HBM explained nearly half of the variance in self-care practice. Perceived severity, perceived barrier, perceived benefits, and self-efficacy were an important factor associated with self-care practice. Tailored message needs to be disseminated to enhance individual's perception towards the disease and self-care practices. In addition, reducing barriers of self-care practice, increasing, perceived severity, perceived benefit and patient's selfefficacy to promote engagement in self-care practice. The HBM can be used to guide interventions and further researches in the study area. In addition, higher educational status, unemployment, being married, having good knowledge about DM, and higher social support were associated with better self-care practices. Health message and counseling for DM patients need to consider these sociodemographic factors and enable them to appreciate and engaged in self-care practices.

\section{Abbreviations}

AOR, adjusted odds ratio; CI, confidence interval; CIRS, chronic illness resources survey; COR, crude odds ratio; DM, diabetes mellitus; HBM, health belief model; IDF, International Diabetes Federation; SD, standard deviation; WHO, World Health Organization.

\section{Data Sharing Statement}

All datasets analyzed related to this article will be made available upon a reasonable request from the corresponding author (Simegnew Handebo, Email: simegnewh@gmail.com). 


\section{Ethical Approval and Consent to Participate}

Ethical clearance was obtained from Ethical review committee of Institute of public health, University of Gondar by a reference number of IPH/180/06/2011. All procedures performed in studies involving human participants were in accordance with the ethical standards of the institutional and/or national research committee and with the 1964 Helsinki declaration and its later amendments or comparable ethical standards. Permission to conduct the research was obtained from Gondar city administration.

\section{Informed Consent}

Informed consent was obtained from each study participant after they were told of the potential risks and benefits as well as the investigational nature of the study.

\section{Acknowledgments}

The authors would like to acknowledge University of Gondar, Institute of Public Health for ethical review. The authors would also like to thank facilitators and the study participants for their dedicated cooperation and made the study possible.

\section{Author Contributions}

All authors made a significant contribution to the work reported, whether that is in the conception, study design, execution, acquisition of data, analysis and interpretation, or in all these areas; took part in drafting, revising or critically reviewing the article; gave final approval of the version to be published; have agreed on the journal to which the article has been submitted; and agree to be accountable for all aspects of the work.

\section{Funding}

There is no funding to report.

\section{Disclosure}

The authors reported no conflicts of interest for this work.

\section{References}

1. Alberti KGMM, Zimmet PF. Definition, diagnosis and classification of diabetes mellitus and its complications. Part 1: diagnosis and classification of diabetes mellitus. Provisional report of a WHO consultation. Diabet Med. 1998;15(7):539-553. doi:10.1002/(SICI)1096-9136(199807)15:7<539::AID-DIA668>3.0.CO;2-S

2. Hussain A, Claussen B, Ramachandran A, Williams R. Prevention of type 2 diabetes: a review. Diabetes Res Clin Pract. 2007;76 (3):317-326. doi:10.1016/j.diabres.2006.09.020
3. Abebe SM, Berhane Y, Worku A, Assefa A. Diabetes mellitus in North West Ethiopia: a community based study. BMC Public Health. 2014;14(1):97. doi:10.1186/1471-2458-14-97

4. Wild S, Roglic G, Green A, Sicree R, King H. Global prevalence of diabetes: estimates for the year 2000 and projections for 2030 . Diabetes Care. 2004;27(5):1047-1053. doi:10.2337/diacare.27.5.1047

5. World Health Organization. Definition, Diagnosis and Classification of Diabetes Mellitus and Its Complications: Report of a WHO Consultation. Part 1, Diagnosis and Classification of Diabetes Mellitus. Geneva: World Health Organization; 1999.

6. Abebe N, Kebede T, Addise D. Diabetes in Ethiopia 2000-2016prevalence and related acute and chronic complications; a systematic review. Afri J Diabetes Med. 2017;25(2).

7. Group IDA. Update of mortality attributable to diabetes for the IDF Diabetes Atlas: estimates for the year 2013. Diabetes Res Clin Pract. 2015;109(3):461-465. doi:10.1016/j.diabres.2015.05.037

8. Cho N, Shaw J, Karuranga S, et al. IDF diabetes atlas: global estimates of diabetes prevalence for 2017 and projections for 2045. Diabetes Res Clin Pract. 2018;138:271-281. doi:10.1016/j.diabres.2018.02.023

9. Roglic G. WHO global report on diabetes: a summary. Int J Noncommun Dis. 2016;1(1):3. doi:10.4103/2468-8827.184853

10. Mbanya JCN, Motala AA, Sobngwi E, Assah FK, Enoru ST. Diabetes in sub-saharan africa. Lancet. 2010;375(9733):2254-2266. doi:10.1016/S0140-6736(10)60550-8

11. Centers for Disease Control and Prevention. National diabetes fact sheet: national estimates and general information on diabetes and prediabetes in the United States, 2011. Dis Control Prev. 2011;201(1).

12. Peyrot M, Rubin R, Lauritzen T, Snoek F, Matthews D, Skovlund S. Psychosocial problems and barriers to improved diabetes management: results of the Cross-National Diabetes Attitudes, Wishes and Needs (DAWN) Study. Diabet Med. 2005;22(10):1379-1385. doi:10.1111/j.1464-5491.2005.01644.x

13. Shrivastava SR, Shrivastava PS, Ramasamy J. Role of self-care in management of diabetes mellitus. J Diabetes Metab Disord. 2013;12 (1):14. doi:10.1186/2251-6581-12-14

14. Wallston KA, Rothman RL, Cherrington A. Psychometric properties of the perceived diabetes self-management scale (PDSMS). J Behav Med. 2007;30(5):395-401. doi:10.1007/s10865-007-9110-y

15. Song M. Diabetes mellitus and the importance of self-care. J Cardiovasc Nurs. 2010;25(2):93-98. doi:10.1097/JCN.0b013e3181c5a364

16. Anderson RM. Patient empowerment and the traditional medical model: a case of irreconcilable differences? Diabetes Care. 1995;18 (3):412-415. doi:10.2337/diacare.18.3.412

17. Polly RK. Diabetes health beliefs, self-care behaviors, and glycemic control among older adults with non-insulin-dependent diabetes mellitus. Diabetes Educ. 1992;18(4):321-327. doi:10.1177/014572179201800411

18. Iregbu S, Iregbu F. A review of self-management of diabetes in Africa. Afri J Diabetes Med. 2016;24(2).

19. Mariye T, Tasew H, Teklay G, Gerensea H, Daba W. Magnitude of diabetes self-care practice and associated factors among type two adult diabetic patients following at public Hospitals in central zone, Tigray Region, Ethiopia, 2017. BMC Res Notes. 2018;11(1):380. doi:10.1186/s13104-018-3489-0

20. Ayele K, Tesfa B, Abebe L, Tilahun T, Girma E. Self care behavior among patients with diabetes in Harari, Eastern Ethiopia: the health belief model perspective. PLoS One. 2012;7(4):e35515. doi:10.1371/ journal.pone. 0035515

21. Addisu Y, Eshete A, Hailu E. Assessment of diabetic patient perception on diabetic disease and self-care practice in Dilla University Referral Hospital, South Ethiopia. J Metabol Synd. 2014;3 (166):2167-0943.1000166.

22. Chali SW, Salih MH, Abate AT. Self-care practice and associated factors among Diabetes Mellitus patients on follow up in Benishangul Gumuz Regional State Public Hospitals, Western Ethiopia: a cross-sectional study. BMC Res Notes. 2018;11(1):833. doi:10.1186/s13104-018-3939-8 
23. Gurmu Y, Gela D, Aga F. Factors associated with self-care practice among adult diabetes patients in West Shoa Zone, Oromia Regional State, Ethiopia. BMC Health Serv Res. 2018;18(1):732. doi:10.1186/ s12913-018-3448-4

24. Aschalew AY, Yitayal M, Minyihun A, Bisetegn TA. Self-care practice and associated factors among patients with diabetes mellitus on follow up at University of Gondar Referral Hospital, Gondar, Northwest Ethiopia. BMC Res Notes. 2019;12(1):1-6. doi:10.1186/ s13104-019-4630-4

25. Glanz K, Rimer BK, Viswanath K, editors. Health Behavior and Health Education: Theory, Research, and Practice. John Wiley \& Sons; 2008.

26. Janz NK, Champion VL, Strecher VJ. The health belief model. In: Glanz K, Rimer BK, Lewis FM, editors. Health Behavior and Health Education: Theory, Research, and Practice. San Francisco: JosseyBass; 2002:45-66.

27. Feleke SA, Alemayehu CM, Adane HT, Onigbinde A, Akindoyi O, Faremi F. Assessment of the level and associated factors with knowledge and practice of diabetes mellitus among diabetic patients attending at FelegeHiwot hospital, Northwest Ethiopia. Clin Med Res. 2013;2(6):110. doi:10.11648/j.cmr.20130206.11

28. Toobert DJ, Hampson SE, Glasgow RE. The summary of diabetes self-care activities measure: results from 7 studies and a revised scale. Diabetes Care. 2000;23(7):943-950. doi:10.2337/diacare.23. 7.943

29. Eigenmann C, Skinner T, Colagiuri R. Development and validation of a diabetes knowledge questionnaire. Pract Diabetes Int. 2011;28 (4):166-70d. doi:10.1002/pdi.1586

30. Glasgow RE, Toobert DJ, Barrera M, Strycker LA. The chronic illness resources survey: cross-validation and sensitivity to intervention. Health Educ Res. 2004;20(4):402-409. doi:10.1093/ her/cyg140

31. Champion VL. Instrument development for health belief model constructs. Adv Nurs Sci. 1984;6:73-85. doi:10.1097/00012272198404000-00011

32. Vazini H, Barati M. The health belief model and self-care behaviors among type 2 diabetic patients. Iran J Diabetes Obes. 2014;6 (3):107-113.

33. Dehghani-Tafti A, Mahmoodabad SSM, Morowatisharifabad MA, Ardakani MA, Rezaeipandari H, Lotfi MH. Determinants of self-care in diabetic patients based on health belief model. Glob J Health Sci. 2015;7(5):33. doi:10.5539/gjhs.v7n5p33

34. Karimy M, Araban M, Zareban I, Taher M, Abedi A. Determinants of adherence to self-care behavior among women with type 2 diabetes: an explanation based on health belief model. Med J Islam Repub Iran. 2016;30:368.
35. Mamo M, Demissie M. Self care practice and its associated factors among diabetic patients in Addis Ababa public hospitals, cross sectional study. J Diabetes Cholest Metabol. 2016;1(1):2-5.

36. Abate TW, Tareke M, Tirfie M. Self-care practices and associated factors among diabetes patients attending the outpatient department in Bahir Dar, Northwest Ethiopia. BMC Res Notes. 2018;11(1):800. doi:10.1186/s13104-018-3874-8

37. Siti Khuzaimah A, Aini A, Surindar Kaur S, Hayati Adilin M, Padma A. Self-care behaviour among type 2 diabetes patients. Pertanika J Sci Technol. 2014;22(2).

38. Amente T, Belachew T, Hailu E, Berhanu N. Self care practice and its predictors among adults with diabetes mellitus on follow up at Nekemte hospital diabetic clinic, West Ethiopia. World J Med Med Sci. 2014;2(3):1-16.

39. Nam S, Chesla C, Stotts NA, Kroon L, Janson SL. Barriers to diabetes management: patient and provider factors. Diabetes Res Clin Pract. 2011;93(1):1-9. doi:10.1016/j.diabres.2011.02.002

40. Bhandari P, Kim M. Self-care behaviors of Nepalese adults with type 2 diabetes: a mixed methods analysis. Nurs Res. 2016;65(3):202-214. doi:10.1097/NNR.0000000000000153

41. Chourdakis M, Kontogiannis V, Malachas K, Pliakas T, Kritis A. Self-care behaviors of adults with type 2 diabetes mellitus in Greece. J Community Health. 2014;39(5):972-979. doi:10.1007/s10900-0149841-y

42. Saleh F, Mumu SJ, Ara F, Begum HA, Ali L. Knowledge and self-care practices regarding diabetes among newly diagnosed type 2 diabetics in Bangladesh: a cross-sectional study. BMC Public Health. 2012;12(1):1112. doi:10.1186/1471-2458-12-1112

43. Kugbey N, Asante KO, Adulai K. Illness perception, diabetes knowledge and self-care practices among type-2 diabetes patients: a cross-sectional study. BMC Res Notes. 2017;10(1):381. doi:10.1186/ s13104-017-2707-5

44. Bai YL, Chiou CP, Chang YY. Self-care behaviour and related factors in older people with Type 2 diabetes. J Clin Nurs. 2009;18 (23):3308-3315. doi:10.1111/j.1365-2702.2009.02992.x

45. Adejoh SO. Diabetes knowledge, health belief, and diabetes management among the Igala, Nigeria. Sage Open. 2014;4 (2):2158244014539966. doi:10.1177/2158244014539966

46. Gopichandran V, Lyndon S, Angel M, et al. Diabetes self-care activities: a community-based survey in urban southern India. Natl Med J India. 2012;25(1):14.

\section{Publish your work in this journal}

Diabetes, Metabolic Syndrome and Obesity: Targets and Therapy is an international, peer-reviewed open-access journal committed to the rapid publication of the latest laboratory and clinical findings in the fields of diabetes, metabolic syndrome and obesity research. Original research, review, case reports, hypothesis formation, expert opinion and commentaries are all considered for publication. The manuscript management system is completely online and includes a very quick and fair peer-review system, which is all easy to use. Visit http://www.dovepress.com/testimonials.php to read real quotes from published authors.

Submit your manuscript here: https://www.dovepress.com/diabetes-metabolic-syndrome-and-obesity-targets-and-therapy-journal 